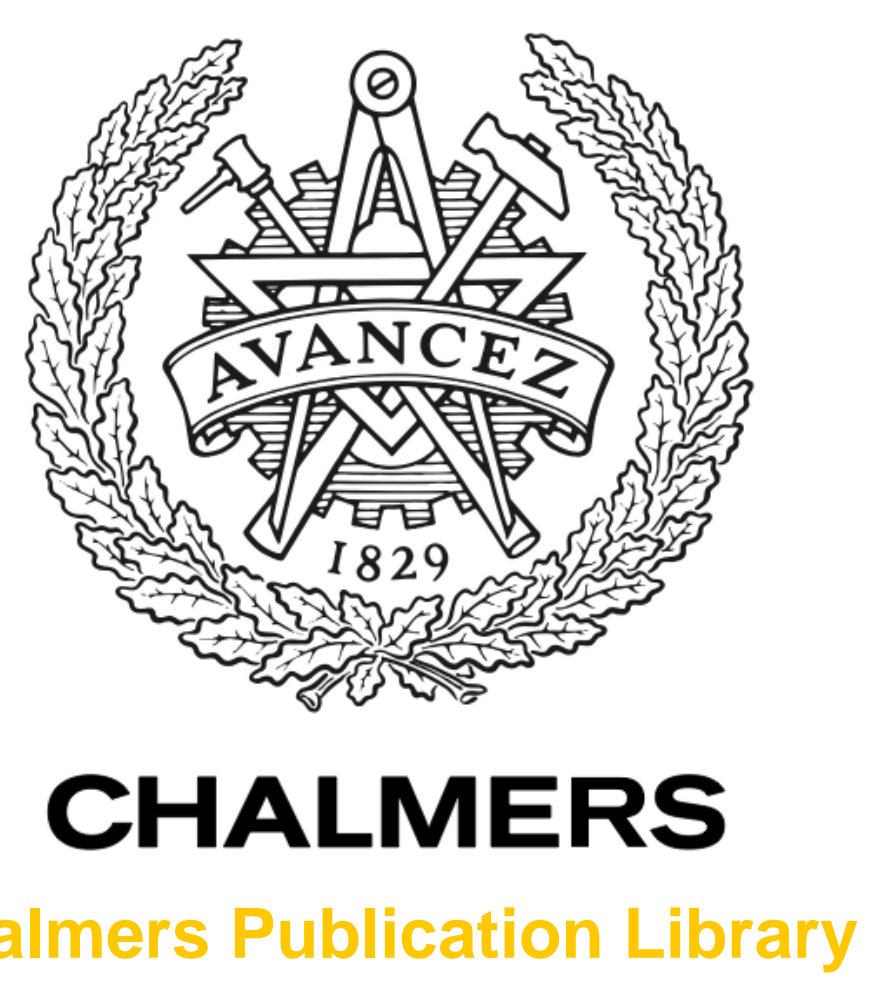

Chalmers Publication Library

\title{
Professional Virtual Worlds Supporting Computer-Mediated Communication, Collaboration, and Learning in Geographically Distributed Contexts
}

This document has been downloaded from Chalmers Publication Library $(\mathrm{CPL})$. It is the author's version of a work that was accepted for publication in:

IEEE Transactions on Professional Communication (ISSN: 0361-1434)

Citation for the published paper:

Bosch-Sijtsema, P. ; Sivunen, A. (2013) "Professional Virtual Worlds Supporting Computer-

Mediated Communication, Collaboration, and Learning in Geographically Distributed

Contexts". IEEE Transactions on Professional Communication, vol. 56(2), pp. 160-175.

http://dx.doi.org/10.1109/TPC.2012.2237256

Downloaded from: http://publications.lib.chalmers.se/publication/174234

Notice: Changes introduced as a result of publishing processes such as copy-editing and formatting may not be reflected in this document. For a definitive version of this work, please refer to the published source. Please note that access to the published version might require a subscription. 


\section{Professional virtual worlds supporting computer-mediated communication, collaboration and learning in geographically distributed contexts}

\author{
Dr. Petra M. Bosch-Sijtsema* \\ (corresponding author) \\ Chalmers University of Technology, Civil \\ and Environmental Engineering, division \\ of Construction Management, Sven Hultins \\ gata $8, \mathrm{SE}-41296$ Gothenburg, Sweden, \\ Phone: +46-31-772-1945 \\ Email: Petra.Bosch@Chalmers.se
}

\author{
Dr. Anu Sivunen \\ Aalto University School of Science, BIT \\ Research Centre / Work Psychology and \\ Leadership. P. O. Box 15500, FI-00076 \\ Aalto, Finland. \\ Anu.Sivunen@aalto.fi
}

Acknowledgements: This study is sponsored by the Finnish Funding Agency for

Technology and Innovation (Tekes), company partners, as well as the MIDE research

program at Aalto University, Finland (http://mide.tkk.fi/en).

Research Problem: Although much research exists on virtual worlds, very few studies focus on professional virtual worlds used for working in a global setting.

\section{Research Questions:}

1. How do global managers currently use and experience professional Virtual Worlds as a communication media for global work?

2. How do these Virtual Worlds support global and professional communication in a geographically distributed context?

Literature Review: We reviewed Virtual World literature in the area of social sciences, education and games. Little research has been conducted on Virtual Worlds for work groups. But those studies support the assumption that Virtual Worlds are suitable for global distributed work as a collaboration and communication medium.

Methodology: With an explorative and qualitative interview research approach we conducted 47 semi-structured interviews with virtual world vendors, researchers, and managers using virtual worlds in their work. Data was analysed based on grounded theory analysis methods.

Results and Conclusions: The results show four different use cases applied for professional Virtual Worlds: small team meetings, trainings, community building, and conferences. Furthermore, our findings confirm Virtual World literature that states that the professional Virtual World as a communication and collaboration tool supports geographically distributed work as well as visualization and learning in a global context.

Index Terms - Computer-mediated communication, collaboration, global distributed work, learning, and professional virtual worlds. 
Published in IEEE Transactions on Professional Communication, 56 (2) p. 160-175

\section{INTRODUCTION}

Increasingly, organizations are working either globally or with a distributed work force. As a result of technological developments in communication media and mobile phones, work is not bound to a particular place or time, but people located in different geographical locations can collaborate and communicate via technology. Many studies on working in a global and geographically distributed context discuss the implications of people collaborating remotely with their colleagues, either while traveling, from home, from another office, or from a customer's site; we call this distributed work. The essential characteristics of distributed work are that employees work over geographical boundaries [1] and to some extent work with computer-mediated communication (CMC) in order to achieve a common goal [2][3].

Literature on distributed work is diverse and covers many different aspects [1]. Therefore, some authors focus on a continuum of variations in the extent of face-to-face work [4] in terms of degrees or discontinuities of distributed work [5]. These discontinuities are factors that contribute to a decrease in cohesion and can include physical location, time zone difference, national culture, professional culture, and organizational affiliation. The discontinuities of location, time zone and culture are often discussed in literature as impacting distributed work negatively [6]- [14]. Furthermore, due to economic difficulties in the market and a focus on decreasing real estate and traveling cost, more and more firms use distributed workers.

Many studies argue that CMC is commonly recognized as an enabler of distributed work [15]- [17], but CMC cannot fully replace face-to-face communication and proximity [1], [18]. For firms working with distributed workers it becomes important to create a working environment in which their remote employees can communicate and collaborate in order to 
Published in IEEE Transactions on Professional Communication, 56 (2) p. 160-175

deliver a task. Many different types of communication tools have been developed over time to support global professional communication. In this article we primarily focus on threedimensional (3D) virtual worlds (Virtual Worlds) as a medium for communication, and study how Virtual Worlds are perceived in professional global settings. Virtual Worlds are communication systems in which multiple interactants share the same three-dimensional digital space despite occupying remote physical locations and in which one can navigate, manipulate objects, and interact with one another, usually via avatars [19],[20]. Avatars are flexible and easily transformed digital self-representations in a graphic 3D form [21]. Virtual Worlds can to some extent increase engagement and feeling of presence, as well as cross geographical boundaries - aspects that are perceived as problematic in distributed work [22]. The popularity of Virtual Worlds is also growing rapidly. The number of registered accounts in different Virtual Worlds rose in 2011 as high as 1,7 billion [23], which makes Virtual Worlds an important media to study from a CMC perspective.

In our research we focus on professional Virtual Worlds, which is a medium primarily targeted to or used in a work context rather than in just socializing or gaming. Most research performed on Virtual Worlds has been game-based in which social, entertainment, and educational themes are important [24].

Virtual Worlds are a rather new medium for professional and global communication and few empirical studies on professional Virtual World usage are published [20]. Therefore, our research questions are the following: (1) How do global managers currently use and experience professional Virtual Worlds as a communication media for global distributed work? (2) How do these Virtual Worlds support global professional communication?

The paper is organized as follows. Below we review literature on Virtual Worlds and their 
Published in IEEE Transactions on Professional Communication, 56 (2) p. 160-175

implications for communication and collaboration. We discuss our methodology in section three and present our main results in section four. In the final section we present conclusions, limitations and suggestions for future work.

\section{LiterATURE REVIEW}

The purpose of this section is to discuss characteristics of Virtual Worlds and how Virtual Worlds can be perceived as collaboration and communication media for distributed work. We first discuss how literature was selected concerning Virtual Worlds. Secondly, we present Virtual World research performed from multiple disciplines. In the next section we discuss how Virtual Worlds support different communication modes for professional communication. We conclude the section by arguing that Virtual Worlds are suitable as media for distributed work.

How Literature Was Selected We first selected literature based on the review on Virtual Worlds performed by Sivunen and Hakonen [20]. Based on this review we applied a snowball technique for finding references to other Virtual World studies. Furthermore, we searched the main electronic databases (such as EBSCO, PsycINFO, Sage, JSTOR, Emerald) for studies in communication, social psychology, education, business, and information systems using relevant terms (such as Virtual Worlds and collaboration, professional Virtual Worlds) to find studies on Virtual Worlds, use cases, or professional Virtual Worlds. We primarily focused on topics of use cases including training, learning, and professional use of Virtual Worlds, as well as the use of Virtual Worlds for distributed work.

Virtual World research Today a vast majority of research on 3D virtual worlds has been conducted in experimental settings, where individuals' perceptions, responses and attitudes towards this new media have been studied (see, for example [25] - [27]). Researchers in the 
Published in IEEE Transactions on Professional Communication, 56 (2) p. 160-175

fields of computer science, psychology, and communication have performed various experiments, like the effects of avatar appearance on user's collaboration patterns [21]; individuals perception of presence and co-presence in Virtual Worlds [28]-[30]; and the impact of verbal and nonverbal communication of avatars operating in Virtual Worlds on individual reactions [31]. For example, Yee and Bailenson [21] found that the appearance of the avatar to which the user is assigned, can impact the self-disclosure patterns of the user and the interpersonal distance between Virtual World users. Other studies researched individual reactions to the presence of other avatars in Virtual World [29] and found positive and negative performance effects on tasks resulting from the presence of others. These findings indicate that the role of avatars as well as the feelings of presence they create can affect users' collaboration with others in virtual worlds.

In the literature, Virtual Worlds are applied for different purposes. Messinger et al. [24] discussed different types of Virtual Worlds, in which the authors only focused on social and game-related Virtual Worlds. These Virtual Worlds focus on socializing and play. They found Virtual World types directed to education and learning, particular communities, play, or Virtual Worlds primarily for children. Others discuss the potential of using Virtual Worlds for training in particular fields such as health [32], education [33][34], or learning in organizations [35][36][37]. Literature in education also discusses the importance of play in leadership development [38]. Professional Virtual Worlds could support play and games for personal development and training in global firms.

Only a minority of studies cover group work and group dynamics in Virtual Worlds, and research exploring collaboration of organizational teams in Virtual Worlds hardly exists (see 
Published in IEEE Transactions on Professional Communication, 56 (2) p. 160-175

review on social and group phenomena in virtual worlds [20]. Such a lack of studies on work groups presents a challenge to the development of Virtual Worlds that are used for work.

One of the few studies conducted in organizational settings and exploring a real-life work group showed encouraging results concerning the use of Virtual Worlds in the work context. This study [39] observed the implementation of a Virtual World communication medium for a work team that only communicated with help of face-to-face meetings. The findings revealed that the meetings held in a Virtual World were considered to be more task-oriented than face-to-face meetings. It was also discovered that graphic avatars played an important role in turn taking and making the meetings more enjoyable.

Despite the lack of research in the area, Virtual Worlds can be seen as a new collaboration and communication tool or workspace, and these environments provide several opportunities for work groups. The possibilities for rich interaction, learning and training via avatars [24], as well as the feelings of social presence are important aspects to consider for Virtual Worlds as media for professional work groups.

Virtual Worlds support different communication modes The collaboration possibilities and communication modes Virtual Worlds provide for work groups are numerous. Virtual Worlds support synchronous communication between several participants but they can also be utilized in an asynchronous manner as knowledge repositories. It is possible to record meetings held in Virtual Worlds, and some parts of the communication, such as text-chat, are usually automatically saved. Also 3D objects created or modified in a Virtual World collaboration session can be stored in the space for future sessions. Previous studies on distributed work (such as [40]) argue that providing a centralized knowledge repository for 
Published in IEEE Transactions on Professional Communication, 56 (2) p. 160-175

distributed workers diminishes the need for person-to-person communication in order to obtain expert information. Furthermore, distributed workers can access information from the repository to eliminate unnecessary communications, which diminishes interruptions and increases perceived effectiveness [40].

In addition to synchronous and asynchronous communication support, Virtual Worlds generally provide several different communication modalities through textual, auditorial, visual and graphical channels. There are many tools available in current Virtual Worlds used for work, such as chat, voice and whiteboards, as well as integration of different applications that support several communication modes. Williams et al. [41] studied the results of different communication channels on individual perceptions in a game-based Virtual World. They found that by introducing voice communication, the player community perceived an increase in enjoyment and trust of the Virtual World. Therefore, different communication channels provided in the Virtual World platforms may have an affect on collaboration in work groups.

In platforms that provide avatars for users, it is possible to convey restricted nonverbal behaviors through certain commands. However, a natural use of such avatar gestures usually requires a prolonged experience in using the platform. With support of the visual and graphical channels provided by the Virtual World it is possible to observe information threedimensionally, such as the position and location of objects and other users. Therefore, Virtual Worlds can be used to facilitate learning that aims to enhance learner's spatial knowledge of the explored domain, as well as exploring physical behavior of objects. The formation of a spatial, cognitive information space can boost the exploration efficiency and conceptual understanding of the learning domain [42]. 
Published in IEEE Transactions on Professional Communication, 56 (2) p. 160-175

Virtual Worlds as media for distributed work Working life is becoming more and more global and companies are simultaneously striving to minimize their travel costs and to find new ways of collaboration. Therefore, we attribute great importance to the research on Virtual Worlds as potential media for distributed work. Despite the lack of studies in the area, Virtual Worlds can be seen as a new collaboration and communication tool or workspace for geographically distributed work groups and organizations (see also [43]). The development of Virtual Worlds, such as Second Life, provides many opportunities, especially for geographically distributed work groups. Such groups are also known as virtual teams, that is, groups of people striving toward a common goal, dispersed in many locations, and communicating with each other predominantly via information and communication technology (such as, [2][3]). Virtual Worlds can provide a common workspace for virtual teams that struggle with communication problems over distance (see [2]).

In Virtual Worlds, prototypes can be modelled and spaces can be visualized together remotely. Virtual Worlds can also provide a more inspiring experience for collaborators by enabling the team members to do several unconventional things in a $3 \mathrm{D}$ environment, such as flying, diving or sitting around a camp fire. Such activities might serve as team-building functions and can strengthen the team members' identification with their distributed team [44].

Even though the research presented in this section shows that the use of Virtual Worlds could be suitable for global and distributed work, few empirical studies provide evidence on how Virtual Worlds are applied in these contexts. Therefore, in our study we want to explore the different use cases for Virtual Worlds that support work groups in general. Moreover, we 
Published in IEEE Transactions on Professional Communication, 56 (2) p. 160-175

want to dig deeper on how Virtual Worlds are experienced by global managers working in distributed environments.

\section{Methodology}

Our research focuses on the following research questions: (1) how do global managers currently use and experience professional Virtual Worlds as a communication media for their global work, and (2) how do these Virtual Worlds support global professional communication? The purpose of the methodology section is to present readers with the research methods for gaining a better insight in the performed study. We first discuss our choice of research methodology in relation to other types of research methods. Second, we focus on how data was collected in terms of participants and interview guide. Finally we discuss the data analysis process applied in the research.

Choice of Research Methodology We choose a qualitative approach over quantitative and critical methodologies, primarily because there is little empirical work performed on Virtual Worlds for work groups in distributed environments. Our research is an explorative and ethnographic study in which we chose a qualitative interview approach in order to capture data on perceptions of local actors 'from the inside' [45]. We decided to collect qualitative data in the form of interviews to explore in-depth how managers work with Virtual Worlds. By interviewing manager-level informants we wanted to gain insight in inclusive accounts based on their personal experience (cf. [46]) of using Virtual Worlds in their global work.

How Data Was Collected In order to collect the data we used semi-structured interviews, in which the interviewee had the ability to discuss their experiences, and the researchers had the opportunity to compare the different interviews. Many of the interviews were held by both researchers in order to obtain a common interview technique. These interviews were 
Published in IEEE Transactions on Professional Communication, 56 (2) p. 160-175

either one-on-one interviews in person or on the phone, or group interviews (with groups of maximum three people). In total we held 47 interviews (see table I). The data collection was divided into three different parts: first we contacted companies and participants who have been working with professional Virtual Worlds and who have either published or presented their work in public. We attended several company presentations (six in total) at conferences. Some companies also supplied secondary material on the Virtual Worlds they used in their firm. Secondly, we conducted semi-structured interviews with 47 participants. The interviews were between 1-2 hours and all interviews were recorded and transcribed. All interviewees read through their transcript interview and confirmed the material. Thirdly, we had the opportunity to observe a total of nine different Virtual Worlds the participants were working with. Several showed their own avatar, the type of Virtual World they were working with, as well as features they used within these worlds. The vendors provided several walk-throughs and both researchers tested out several of the Virtual Worlds in their own research group.

Participants: Of these 47 interviews we held six interviews with vendors of well-known professional Virtual Worlds to gain an insight in the current market of Virtual World platforms and their possibilities. Furthermore, we held two interviews with researchers who specialize in Virtual World research and consulting. We held 39 interviews with managers of 12 different global (Fortune 100 and 500), US, and EU-based companies who all had experience in using professional Virtual World in their company (see Table I). The companies were mainly selected because they presented their Virtual World experiences externally (outside the company) in articles, blogs, or at conference presentations, and some were selected based on vendor contacts. Participants were recruited either face-to-face at conferences, via email, and with help of networks of research experts within the field of professional Virtual Worlds. In some cases we received names of experienced participants 
through senior management. The common characteristics sought after for the interviewees was that they should have experience in working with Virtual Worlds professionally for their distributed work. The research did not go through an Institutional Review Board but the participants' identities were safeguarded through NDA contracts; all participants and companies were kept anonymous; and all participants as well as the management/or communication department could read through the transcript of their interview and comment on it.

Table I: Overview of the type of companies and number of interviews held.

\begin{tabular}{|l|l|l|l|}
\hline Company type & $\begin{array}{l}\text { Number of } \\
\text { interviews }\end{array}$ & $\begin{array}{l}\text { Individual/group } \\
\text { interview }\end{array}$ & Main use cases \\
\hline Vendors & 6 (US, EU) & Individual & \\
\hline Researchers & 2 (US) & Individual & Meetings, training, and \\
\hline Users: high tech industry & $\begin{array}{l}26(\mathrm{US}, \text { South } \\
\text { America, EU, Asia) }\end{array}$ & Individual & Meetings and training \\
\hline Users: energy companies & 7 (US, EU) & $\begin{array}{l}\text { Group (2) and } \\
\text { individual }\end{array}$ & $\begin{array}{l}\text { Group (1) and } \\
\text { individual }\end{array}$ \\
\hline $\begin{array}{l}\text { Users: medical training \& } \\
\text { pharmaceutical industry }\end{array}$ & 3 (US) & Individual & Communities and conferences \\
\hline Users: associations & 3 (US) & & \\
\hline Total 12 companies & 47 & & \\
\hline
\end{tabular}

Interview Guide: The interviews were structured according to a number of topics:

1. General questions on the function, role, and particular experience of the interviewee in using professional Virtual Worlds.

2. The topic of benefits and challenges of Virtual Worlds focused on how Virtual Worlds were used, for what kind of activities, how Virtual Worlds were used for distributed work, as well as benefits and challenges of working with Virtual Worlds. For these questions we asked for examples from the managers based on their own experience.

3. Media aspect questions focused on the type of Virtual Worlds the interviewees were using, why they had chosen this particular Virtual World, what technological features it had, and how interoperable it was with other systems. For this question several 
Published in IEEE Transactions on Professional Communication, 56 (2) p. 160-175

participants showed the type of Virtual World they were working in and we could observe this.

4. Innovativeness took up questions on creativity and how Virtual Worlds were used to support innovation and creativity.

5. Social processes questions focused primarily on the use of avatars, appearance of avatars and interviewees' identification with their avatars. Along with the interviews we received white papers on company studies or conference/journal articles based on studies performed within the particular companies.

The interview guide was developed, checked, and tested iteratively in a larger and multidisciplinary research group of five people.

Data Analysis Both researchers coded, labeled and categorized the data iteratively through systematic stages [47]. We used a qualitative approach based on the methodology of grounded theory that was influenced mainly by Lincoln and Guba [48]. They base their analysis method exclusively on Glaser and Strauss [49], but limit their scope to the data processing aspects rather than theory development, as in grounded theory [48]: 340]. Our data analysis was performed in a three-step process [45]. The first step was data reduction in which we applied open coding of all the data to tease out dominant themes. The second step involved focused coding in these themes to extract passages related to these four main themes. We categorized sub themes according to how often they were mentioned by interviewees: dominant themes were mentioned in $80-100 \%$ strong themes in $50-80 \%$, and weak themes in $30-50 \%$ of all interviews. The third step was data display in which we made lists and tables of emerging themes and monitored the internal cohesion of the codes. 
Published in IEEE Transactions on Professional Communication, 56 (2) p. 160-175

The coding of the interviews was an iterative process between the two researchers in order to increase validation. A third researcher was involved in a later stage and performed an independent coding procedure that was compared to the codes performed by the two authors. Only a few discrepancies were found during this coding process between the different researchers, which were then discussed and unified. Furthermore, the conclusions drawn from the codes were presented to some of the companies involved in the study.

\section{RESULTS}

The purpose of the result section is to present and discuss the main results from the data collection. The result section is divided into four subsections. The first subsection discusses use cases found for professional Virtual Worlds, which were team meetings, training, communities, and conferences. After that we focus on themes that discuss global and distributed work support with help of Virtual Worlds. The third section presents themes on Virtual Worlds supporting visualization and learning. The final section takes up challenges of professional virtual worlds that came out of the data.

We interviewed managers who had experience in working in globally distributed environments and who used professional Virtual Worlds to support their work. The managers worked with several different types of professional Virtual Worlds, some tailor made within their own firm, some open source platforms or proprietary Virtual World platforms. However, many of these worlds offered common features and functioned in a secure environment and behind the company firewalls. The most important feature in relation to other ICT was the feature of visualization, use of professional avatars, video, 3D models, as well as scenarios and real-life situations not restricted by physics laws or scale. Other features professional Virtual Worlds supported were the ability to share and edit information, files and documents, ability to store documents files, whiteboards and sticky notes, 
Published in IEEE Transactions on Professional Communication, 56 (2) p. 160-175

possibility to record sessions and discussions, possibility to make connections to other internal systems in the company, and options to have more private conversations in either chat or in silent areas in which nobody else in the world can hear you. The interviewed managers were all represented in these professional Virtual Worlds by $3 \mathrm{D}$ avatars.

Use Cases of Professional Virtual Worlds One of the results we found from the interviews was that these interviewees mainly applied the Virtual Worlds for four types of use cases: small team meetings, training, communities, and conferences (See table II).

Several participants used the Virtual Worlds for small team meetings in teams that have geographically distributed members. This use case is considered a weak theme with $41 \%$ of interviewees applying Virtual Worlds in small team meetings. The second and most popular use case reported by many participants, was the use case of training of employees and leaders. This strong subtheme was discussed by $51 \%$. These Virtual World training sessions were either leadership development, working in multicultural settings, or learning how to speak in public. Several participants discussed that they applied the Virtual Worlds for more hands-on training. A third use case we found was that the Virtual World was applied to build social networks and virtual communities. Around 33\% of interviewees mentioned this use case, which is considered as a weak subtheme. The Virtual Worlds presented the benefit of developing social networks in terms of opportunities to meet people informally and formally, and mix with peers, or having access to expertise in a community represented in the Virtual World. The last use case that was discussed was only mentioned by a small group of interviewees (23\%), but it still presents an interesting finding. A part of the participants applied the Virtual Worlds for large conferences of more than 100 people. Here the Virtual Worlds represented a conference site in which people could listen to presentations, download 
slides and information, chat with conference people and presenters and could access the

repository of presentations and discussion after the conference.

Table II: Use cases for professional virtual worlds

\begin{tabular}{|c|c|}
\hline $\begin{array}{l}\text { Use Cases of } \\
\text { professional } \\
\text { Virtual Worlds }\end{array}$ & Examples of quotes \\
\hline $\begin{array}{l}\text { Small team } \\
\text { meetings }(41 \%)\end{array}$ & $\begin{array}{l}\text { - I've been organizing weekly virtual meetings with my team. So, in fact, it was } \\
\text { replacing the weekly staff meetings, which at [company name] I've done mostly } \\
\text { using traditional audio conferences.... There were people from the United States, } \\
\text { from United Kingdom, and from France. And sometimes people from China, from } \\
\text { Australia, so people were from everywhere. And the activities were conversations } \\
\text { between people. But also most of the time, people presenting some slideshow } \\
\text { concerning their own activities with [company name] during the last week, and also } \\
\text { the plans for the coming weeks. So, it was quite simple meetings, but very } \\
\text { interesting. And something that almost all distributed companies has a need for. }\end{array}$ \\
\hline Training (51\%) & $\begin{array}{l}\text { - You can do things here [in virtual world] that you cannot do in the refinery. I mean I } \\
\text { can't flip a compressor around in the refinery but I can do it here. I can see what it } \\
\text { looks like underneath. I can see what it looks like from different perspectives. I can } \\
\text { climb up and look down on it and if I have a smart enough compressor in there, I can } \\
\text { peel it away and see what's going on inside, which you can't do in the refinery. And } \\
\text { put it back together. I can attach real-time data to that compressor and look at it in } \\
\text { three dimensions, which, currently, I can't do. [...] So from a training aspect, there are } \\
\text { things I can do which appeal to the human psyche, the way that we learn, the way that } \\
\text { we communicate - the way that we retain knowledge and I can exercise that } \\
\text { knowledge in this virtual space numerous times - which reinforces the ability to retain } \\
\text { the content. }\end{array}$ \\
\hline $\begin{array}{l}\text { Community } \\
\text { /social network } \\
(33 \%)\end{array}$ & $\begin{array}{l}\text { - Our task has been to really bring the [global] community together... And so in the } \\
\text { environment where we can't travel, we really need people talking to each other, } \\
\text { working with each other, mentoring, sharing, connecting and building social capital, } \\
\text { we needed different ways to enhance that socialization. The conference calls are } \\
\text { pretty flat, and so what we wanted to do was to find ways to enhance the environment } \\
\text { and make it feel more as if people were there with each other. So we've been using } \\
\text { the virtual world - .... we've used them as the way that people can bump into each } \\
\text { other, because we set up a big meeting space so that the avatars could be there and } \\
\text { people could sort of connect with people they hadn't connected with through the year. }\end{array}$ \\
\hline $\begin{array}{l}\text { Conferences } \\
(23 \%)\end{array}$ & $\begin{array}{l}\text { - You're standing in a virtual space (conference), and there's } 30 \text { or } 40 \text { or } 50 \text { people in } \\
\text { there, and you see a nametag of somebody across the room and you've heard their } \\
\text { name before, but you've never actually met them. Well, on a conference call, you } \\
\text { would never get the opportunity to walk up to them in a conference call and meet } \\
\text { them. In a virtual space, you can do that. }\end{array}$ \\
\hline
\end{tabular}

These findings on use cases are often discussed in Virtual World literature, even though they are more often discussed in the area of social or game related Virtual Worlds [24]. The benefits of applying Virtual Worlds for training and education have been widely discussed in literature $[33][34][35][36][37]$, and also the social community and network as well as possibilities for larger groups (conferences) are taken up [24]. One use case that is however 
hardly discussed in literature is the use case for distributed team meetings. Although other

ICT is used in this respect, the Virtual World might be an additional technology applicable

for global team meetings.

Global and Distributed Work Support We found a number of themes that supported our research question that Virtual Worlds could support global and distributed work. These

include cost reductions, space for interaction, authentication and security, and professional

avatar representation. A selection of quotes from the data is presented in table III.

Table III: Global and Distributed Work Support data

\begin{tabular}{|c|c|}
\hline $\begin{array}{l}\text { Global and } \\
\text { distributed work } \\
\text { support }\end{array}$ & Examples from Quotes \\
\hline $\begin{array}{l}\text { Cost reductions } \\
(83 \%)\end{array}$ & $\begin{array}{l}\text { - And given travel costs, given hotel costs, given venue costs; that [for traditional } \\
\text { conferences] were a huge expense that the company had to realize. It also took people } \\
\text { away from their job where they had to travel to get there. So, I think in those types of } \\
\text { situations, virtual can do a good job. [...] And then people who are either in far away } \\
\text { locations or really can't afford to take themselves away for that long to travel, they can } \\
\text { attend virtually and actually get the benefit of viewing much of the content. } \\
\text { - Significant cuts in costs of travel. You have a meeting - each person would probably } \\
\text { cost } \$ 1000 \text { in travel - depending on where they're coming from. There's - it's a couple } \\
\text { of days meeting so travel costs are significant, so in addition to costs of - there's a time } \\
\text { cost. For example, heads of research cannot take one or two days to go visit a meeting } \\
\text { somewhere, interact for several hours with a scientist and then disappear and go } \\
\text { somewhere else again. }\end{array}$ \\
\hline $\begin{array}{l}\text { Space for } \\
\text { interaction }(93 \%)\end{array}$ & $\begin{array}{l}\text { - So every team can have a project room that's dedicated to only their work. You never } \\
\text { have to share a conference room with anyone else and you can spread all your materials } \\
\text { on the walls and every time you go in, it's just your stuff and you never have to tidy it } \\
\text { up and -- every team can have their own place. And they find it a very powerful } \\
\text { metaphor that when people get together because they've all been to these rooms before, } \\
\text { everyone knows where things are. And we find that the 3D environment gives people a } \\
\text { spatial navigation, that they can actually navigate through content because, oh, I know } \\
\text { on this wall there's stuff and on the blue wall there's other stuff, and they find that's } \\
\text { very helpful as a way to think about organization of information. And so that's very -- it } \\
\text { turned to be a very powerful aspect of the environment. } \\
\text { - We have a group of engineers ... They are one of the top-performing engineering groups } \\
\text { as far as delivering things on time. And a lot of these things they are collaboratively } \\
\text { working on. What they actually do is that they're constantly sitting in Second Life. } \\
\text { They actually sit in there, you know, in an oilrig that they've built that has all the oilrig } \\
\text { sounds. There are always no less than two people that will be in there. And, you know, } \\
\text { so what they've set up as an environment that, you know... all right, there's a big project } \\
\text { that we need to do. We need some heads down and we'd collaborate with each other. } \\
\text { We may book a meeting room and we'll walk going to the meeting room. We all sit } \\
\text { around and we just really - you know, we collaborate at a much higher level and } \\
\text { therefore - I mean move things sort of really quickly. They've translated that into a } \\
\text { virtual world so they're sitting in there. If you want to go and talk to them, you can - } \\
\text { you just go in and walk over to their area and then they'll be - there'll be a few of them } \\
\text { there at the same time. They're not all at the same location physically but they are }\end{array}$ \\
\hline
\end{tabular}




\begin{tabular}{|c|c|}
\hline & virtually. \\
\hline $\begin{array}{l}\text { Authentication } \\
\text { and security } \\
(55 \%)\end{array}$ & $\begin{array}{l}\text { - When we work here behind the firewall, you look at these strange avatar names that you } \\
\text { hide behind outside [non professional Virtual Worlds]. You know, you meet here } \\
\text { [professional Virtual Worlds] with your [company] names. People are much more } \\
\text { confident, they know who they're talking to, and anyways, they can also disclose things } \\
\text { that may just stay behind the firewalls. } \\
\text { - More importantly, behind that avatar, we could fill out a complete profile. And so there } \\
\text { was as an importance for them that the avatar in front of them as closely resembles the } \\
\text { individual as possible. Well, they have a limited avatar set, but behind the avatar they } \\
\text { have a whole profile page. So there's a whole social networking site behind (the Virtual } \\
\text { World). It runs alongside it, where you can enter in your knowledge and experience, } \\
\text { photographs, video, anything to describe yourself and you can even write a blog if you } \\
\text { want to. }\end{array}$ \\
\hline $\begin{array}{l}\text { Professional } \\
\text { avatar } \\
\text { representation } \\
(79 \%)\end{array}$ & $\begin{array}{l}\text { - I can wave at Jim and I can nod my head and let him know I understand, and shake it if I } \\
\text { don't understand or if I don't agree, or go tap him on the shoulder and say, hey, come } \\
\text { over here and pay attention, you got me into this now } \\
\text { - I thought there was one particular scene in those, a pilot where they made us walking } \\
\text { together to another room ... And I thought it was an interesting experience just for me } \\
\text { personally that this joint walk, with my avatar and my actual colleague's avatar has } \\
\text { indeed created some sort of rapport that made the subsequent - a discussion with } \\
\text { somebody you just met for the very first time more familiar than if you wouldn't, you } \\
\text { know, meet with the person for the first time, say, just on a chat or you're at a } \\
\text { conference or on the telephone. }\end{array}$ \\
\hline
\end{tabular}

Cost Reductions: Many interviewees stated that due to the economic recession and new developments in communication technology, companies worked more and more with distributed workers who communicated mainly through CMC. Interviewees reported that they applied the Virtual World for global and distributed work. The contribution of using Virtual Worlds for distributed work was to a large extent perceived in terms of cost reductions. These cost reductions were found as a dominant subtheme with $83 \%$ of interviewees discussing this benefit. Cost reductions specified into costs for traveling, costs for travel time and time being away from the office, costs for meetings and booking meeting spaces. For these interviewees the cost reduction and reduce in traveling was an important benefit and reason to work with Virtual Worlds.

Space For Interaction: Almost all interviewees mentioned that the Virtual Worlds presented a 'space' in which geographically distributed employees could meet and interact, both formally as well as informally. The space for interaction was found as a dominant theme as 
Published in IEEE Transactions on Professional Communication, 56 (2) p. 160-175

$93 \%$ of interviewees discussed this aspect. Several interviewees mentioned that Virtual Worlds could not replace face-to-face interaction, but compared to more traditional communication media like phone, videoconference, and email, the Virtual World brought a feeling of presence and sense of being together which was not possible with traditional media. People feel more engaged in participating in Virtual Worlds and do not work on other things at the same time.

Several managers reported that their company worked with virtual team rooms, such as a fixed space in the Virtual World for a geographically distributed team. In these team rooms, teams could collaborate and their work, data and information can persist in the room. Team members have the possibility to navigate through the persistent information.

Several companies also used the Virtual World in order to set up a space to meet with a community in a particular field, such as the financial and software communities. These communities used the Virtual World to meet for conferences or presentations. Furthermore, some communities applied the Virtual World for contests and setting up particular research projects within the community on which people could work together. Often this work was performed in their free time, since many of the communities were voluntary and based on employees' own interest to participate.

The professional Virtual Worlds can provide a "space" where people can meet and communicate synchronously in team rooms, meeting places, or even natural environments like a garden. This finding is in line with Davis et al. [22], who discuss the suitability of Virtual Worlds for virtual teams in terms of support in coordination, trust, role clarity and shared understanding. The usage of a professional Virtual World was perceived as improving 
Published in IEEE Transactions on Professional Communication, 56 (2) p. 160-175

a social bonding through informal interaction, possibilities for informal conversations, and sharing experiences in a common space - the virtual world. The common space is an important attribute to support social bonding in geographically distributed settings (cf. [50]). The Virtual World also presents a "space" to communicate asynchronously in terms of a knowledge repository that can be applied over time zones (cf. [40]). In this space, employees are able to access content as well as navigate through this content that can be presented visibly in the Virtual World. The technological feature of Virtual Worlds of having a knowledge repository was often mentioned as an important benefit for many geographical distributed groups who did not share a common time zone.

Authentication and Security: An aspect perceived by several interviewees as relevant was that the Virtual Worlds were often linked to a company profile or social network profile. In such a way authentication of the avatar/member was possible. This strong subtheme was discussed by $55 \%$ of all interviewees. Several interviewees mentioned that this was important in order to get to know the other members. As geographically distributed team members may have never met one another in real life it feels safe to be able to find out who the person behind the avatar is and where $\mathrm{s} /$ he is located in the organization. Many used this feature to discover more about their colleagues' expertise and experience.

Firms can gain access to novel information through employees' social networks or ties by bridging otherwise disconnected sub units and remote site offices to one another [51][52]. With the possibility of connecting Virtual Worlds with companies' profile pages and social media applications the use of Virtual Worlds for social networking becomes even more valuable. Furthermore, the possibility to provide profiles of members in terms of expertise and social networks, helped members to authenticate their co-workers and provided a safer 
Published in IEEE Transactions on Professional Communication, 56 (2) p. 160-175

environment to disclose sensitive information. Many felt that the authentication of professional Virtual Worlds supported an atmosphere for building trust, which is often perceived as difficult in distributed work literature [53].

Professional Avatar Representation: All studied professional Virtual Worlds used avatars to represent the participants (except for one platform). In most Virtual World environments the avatar receives a large amount of attention, however, in the professional Virtual Worlds the avatar is portrayed as professional, and is often dressed in a suit or formal clothing or in clothing directed to a particular line of business (such as a lab coat or coverall). The professional avatar representation was found to be a strong subtheme with $79 \%$ of interviewees discussing this aspect. It was clear however, that the use of avatars differed depending on the tasks, role and setting in which the Virtual World was used. Several interviewees mentioned that when you have smaller meetings in Virtual World with geographically distributed people, it is important to represent the team members as avatars. Interviewees perceived the presence of avatars as meaningful in order to see for example who was talking and who raised a hand. However, in other cases the avatar was perceived as less important and several interviewees mentioned that the use of an avatar was often depended on the task at hand or the situation. Others mentioned the feeling of comfort and freedom when they discussed the use of avatars in their work. They felt that the avatar made them feel safer, comfortable, and free to behave in the virtual work environment. Interviewees discussed that the avatars enfranchised and empowered people to work professionally in the Virtual World. The subtheme of professional avatar representation is closely connected to the subthemes of space for interaction and authentication and security, in terms of representation as avatars provided managers to feel safe and comfortable to interact. The option for employees to be represented as a professional avatar in the virtual space also positively 
impacted communication. The possibility to create presence through avatars [29][30], such as the feeling of being there could help overcome the difficulties known in distributed work. The notion of creating a sense presence is a well-known attribute of Virtual Worlds (see [22]).

The results presented above show that professional Virtual Worlds are suitable communication media for global and distributed work. They support geographically distributed work by providing a space to communicate and interact, giving access and possibilities to navigate through data and information, bringing security with help of authentication and profiles of users, and providing professional avatars.

Virtual Worlds Supporting Visualization and Learning Many managers reported the Virtual World was particularly beneficial for visualization of data, learning, and knowledge transfer. This kind of support was found in several aspects (see table IV for quotes from the data).

Table IV: Virtual Worlds supporting Visualization and Learning

\begin{tabular}{|c|c|}
\hline $\begin{array}{l}\text { Visualization and } \\
\text { Learning }\end{array}$ & Examples of quotes \\
\hline $\begin{array}{l}\text { Visualizing } \\
\text { content }(98 \%)\end{array}$ & $\begin{array}{l}\text { - I think it's an important element of helping to foster the creativity and extend the } \\
\text { brainstorming. Because often times what may happen is that your colleague might } \\
\text { write something down that you see on the board that gets you thinking about } \\
\text { something else that you haven't thought about. So, now you're scribbling a new } \\
\text { idea, you put that up. And somebody else sees that and it takes them in a slightly } \\
\text { different direction. So that concurrent activity allows people to feed off of each } \\
\text { other. And that's really where the productivity-or the creativity in a brainstorming } \\
\text { session comes from. } \\
\text { - I would say virtual environments don't change that at the highest level but they do } \\
\text { make it such that you can work more effectively together with less face-to-face. You } \\
\text { can build trust faster than a telephone call and in part, that's because each of us can } \\
\text { see the actions of each other. In a virtual environment, we have avatars, which we } \\
\text { drive around and I can watch you work, which is not true with other technologies. } \\
\text { So we have a highly immersive but also highly shared environment where I can } \\
\text { watch your keystrokes, I can watch your mouse movements and you can watch mine. } \\
\text { It's symmetric in that we can see each other so if we were talking about something } \\
\text { and you took an action item and you could say, "Well, xx, I'm going to get started }\end{array}$ \\
\hline
\end{tabular}




\begin{tabular}{|c|c|}
\hline & $\begin{array}{l}\text { right away on helping you with that," I could literally, if I chose to - I may not choose } \\
\text { to - but I could watch you working. }\end{array}$ \\
\hline $\begin{array}{l}\text { Training } \\
\text { Hazardous and } \\
\text { Difficult Tasks } \\
(47 \%)\end{array}$ & $\begin{array}{l}\text { - We've modeled explosions on an offshore oil platform that includes the smoke } \\
\text { coming out of it. That's not something that you would want to do in the physical } \\
\text { world. But our behavior is something that you can't add in to programming logic } \\
\text { every possible reaction that someone would make. So in our case, you know, when } \\
\text { the explosion happened and plume smoke came up and people were told to go and } \\
\text { put their hazardous material suits on, and the people who didn't when the smoke } \\
\text { came in and hit them - they were knocked unconscious. What that means is that the } \\
\text { others have to not only do their original jobs but had to take us - put us on a } \\
\text { stretcher, take us over to the heliport and call in for a helicopter to come in and put us } \\
\text { on there and take us all. There's no way you can program those sorts of things. }\end{array}$ \\
\hline $\begin{array}{l}\text { Simulations, } \\
\text { Role-Plays, } \\
\text { Scenarios (72\%) }\end{array}$ & $\begin{array}{l}\text { - And by what I mean by role-playing is the ability to have a new learner practice in a } \\
\text { very realistic environment ... Yes, you can take a worker and put them in a very } \\
\text { realistic looking building but the ability to role-play very easily in a variety of } \\
\text { scenarios, you cannot do with Web conferencing, you can't do with video } \\
\text { conferencing very easily. And we have the ability to play back the practice session. } \\
\text { - in the learning circles, this really helps workers - not just get presented on what a } \\
\text { new skill is but to now go out and practice that, especially in a team context. So it's } \\
\text { not just me doing my job but maybe I have to interact with other colleagues in a } \\
\text { work environment. So if you bring them together and then role-play that work } \\
\text { environment across different scenarios, that is a very compelling feature that is in the } \\
\text { learning and training area very, very critical. } \\
\text { - Inclusive leadership involves working with people to help them understand that there } \\
\text { are various barriers in the workplace regardless of where you work, and you're going } \\
\text { to encounter scenarios where maybe a person maybe only works from a wheelchair } \\
\text { or maybe a person is blind or another person has some kind of disability or a problem } \\
\text { in the workplace that doesn't really allow them to work in a traditional way. So what } \\
\text { are the methods and approaches we can bring these people together? And again, we } \\
\text { physically have to bring them together from all over the world to be able to learn } \\
\text { about what it's like to work with a disability. But we also wanted to immerse in } \\
\text { scenarios, make them understand and feel what it was like to be that person. }\end{array}$ \\
\hline
\end{tabular}

Visualizing Content: An important feature of the Virtual World, which was mentioned by many managers, was the fact that the Virtual World can help to visualize models, drawings, objects and data that is more difficult to obtain when using more traditional media. This theme is considered a dominant subtheme with $98 \%$ of interviewees discussing this aspect. Visual representation of data is found to enable individual sense making in data exploration tasks [54]. Visualizations of data and information can also be perceived as artifacts of knowing, which are symbolic representations through which ideas are articulated, developed, and exchanged [55]. The visualization brought possibilities to communicate in a different way in a distributed work context and helped creating more awareness and understanding of different insights, ideas, and cultures. 
Published in IEEE Transactions on Professional Communication, 56 (2) p. 160-175

Training hazardous and difficult tasks: Several managers reported that they used the Virtual World to perform tasks or train aspects, which are very difficult to perform or train in real life. This use case was a weak sub-theme (47\%) and it was perceived especially important in the energy and medical training industry. One of the major benefits for using a Virtual World in this type of training was to avoid hazardous training situations and risks, and offering a safe environment for training. This type of learning is often best learned by scenarios, roleplays, and hands-on training, which can be rehearsed often. Such training for large global firms, is often costly and time consuming since members have to either work with a mentor or come together in a collocated place for this training.

Simulations, role-plays and scenarios for learning: In order to train various tasks at work situations, managers reported that they used simulations, role-plays or scenarios that employees could repeatedly work with. This was a strong sub-theme mentioned by $72 \%$ of the interviewees. For this training, Virtual Worlds were presented as mirror worlds that closely represented real life as well as simulations and scenarios for training. For example in training on cultural awareness, role-plays were applied to learn about other member's culture. These learning situations could in certain cases be replayed or re-trained in order to learn from mistakes, or train a specific task in a satisfactory manner.

Based on the interview data discussed above Virtual Worlds are beneficial in transferring knowledge. Transferring knowledge is perceived as how knowledge acquired in one situation can be applied in another situation (cf.[56]). First, the Virtual World supports the transfer of know-what knowledge in terms of data and information and visualizations of this data. Second, the Virtual World supports the transfer of know-who knowledge, which comprises of knowledge about different expertise of members, as well as the developments of social 
Published in IEEE Transactions on Professional Communication, 56 (2) p. 160-175

networks. Third, know-how knowledge in terms of learning by doing is transferred during training, simulations, and role-plays that are made possible in Virtual Worlds. Other literature discusses knowledge transfer through training [57] in terms of near and far knowledge transfer. Near transfer in which learning to situations is similar to those in which initial learning has taken place, like in the examples of medical training, or training for hazardous and difficult tasks. Next to near transfer, the authors describe far knowledge transfer as the application of learning to situations dissimilar to those of the original learning events. Especially the scenarios (see quote on inclusive leadership) and role-plays can be used to transfer far knowledge through virtual world training.

The use of virtual worlds in supporting learning and knowledge transfer can be related to Orlikowski's [58] principle of knowing in practice. The Virtual World can support knowing in practice by learning by doing practices in order to develop knowledge on certain capabilities through training, such as hands-on training, and mentoring. This is confirmed in literature discussing the educational use of Virtual Worlds in either medical training [32]), pedagogical use [33][34] and company training [36][37]. Furthermore, Virtual Worlds support in team innovation and learning [35]. Many Virtual World researchers claim the benefits for learning and training in Virtual Worlds in terms of situated learning, offering a space where people can create and receive training, or mirror the real-life world [35]. However, few studies confirm empirically the suitability of Virtual Worlds for learning in a global firm.

The professional Virtual Worlds supported visualization and learning by visualizing the content to other users, through presenting possibilities to learn hazardous and difficult tasks, and by enabling simulations, role-plays, and scenarios to learn about different situations and behavior. 
Challenges of Professional Virtual Worlds All interviewees mentioned that their

companies were still in a starting phase in applying Virtual Worlds for global work and they mentioned a number of challenges for using Virtual Worlds in a work context. The

challenges were the adoption difficulties, technological standards, lack of natural gestures of avatars, and experience in using Virtual Worlds and other social networking or gaming tools (see examples of the data in table $\mathrm{V}$ ).

Table V: Challenges of professional Virtual Worlds data

\begin{tabular}{|c|c|}
\hline Challenges & Examples of quotes \\
\hline $\begin{array}{l}\text { Adoption } \\
\text { Difficulties } \\
(55 \%)\end{array}$ & $\begin{array}{l}\text { - Another thing that's very important is we constantly have to make sure that it's not } \\
\text { thought of as a game and, you know, it's like - we'll have fun with it but we won't } \\
\text { have too much fun since then people will see this is as an entertainment mechanism } \\
\text { versus really a work mechanism } \\
\text { - I think there's a real conflict between the gaming use and the use for technical } \\
\text { purposes ... going to have to cross. What I see is a number of people who had } \\
\text { experiences with Second Life in the gaming context. So sort of have images of it as } \\
\text { a gaming phenomenon. And so now when they see it as we're using it, they don't } \\
\text { think that it's good as-they don't think the environment's as good as what they've } \\
\text { seen in games. But they also don't see it as a serious tool yet, so it's kind of a funny } \\
\text { mix. }\end{array}$ \\
\hline $\begin{array}{l}\text { Technological } \\
\text { Standards }(72 \%)\end{array}$ & $\begin{array}{l}\text { - One of the issues that I think is there with the virtual worlds is that this hardware that } \\
\text { you require is pretty-you need a lot of hardware, like if not a graphics card, at least } \\
\text { a high amount of RAM is needed. So these are some of the issues that I think that } \\
\text { virtual worlds face. Many of the laptops that currently our employees have do not } \\
\text { work very well in a virtual environment, so they have to, start going for a desktop } \\
\text { later on. And so this could be one of the issues that could be there in the virtual } \\
\text { world. You need a lot of investment in hardware }\end{array}$ \\
\hline $\begin{array}{l}\text { Lack of Natural } \\
\text { Gestures of } \\
\text { Avatars }(36 \%)\end{array}$ & $\begin{array}{l}\text { - If they could make the emotions come through in the avatar as well as the lips and } \\
\text { everything moving, that is another thing that I think will greatly enrich the } \\
\text { experience. And, you know, it'll make it easier for people to adopt } \\
\text { - It feels-it's so foreign to people so there's a lot of startup problems with it, it's } \\
\text { not-I don't think it's real intuitive as you get in and have to move around. }\end{array}$ \\
\hline $\begin{array}{l}\text { Experience in } \\
\text { Using Virtual } \\
\text { Worlds and } \\
\text { Other Social } \\
\text { Networking or } \\
\text { Gaming Tools } \\
(49 \%)\end{array}$ & $\begin{array}{l}\text { - If you have people who - if the most they use is email, there's kind of a limit to } \\
\text { what they're willing to do. They won't go and fill out an extensive profile; they } \\
\text { won't proactively try and engage in chats with people. They're more observers in } \\
\text { the environments. And then you have people that [...] they're on Facebook and } \\
\text { they're on LinkedIn and they're using more social networking tools, and they know } \\
\text { what blogs are and they know what Twitter is. They're like ready to take the next } \\
\text { leap, and they'll do more and they're less afraid of revealing who they are and } \\
\text { interacting with people they don't really know. }\end{array}$ \\
\hline
\end{tabular}

Adoption Difficulties: The adoption of Virtual World technology as part of global work was a strong subtheme and discussed as a challenge by $55 \%$ of the interviewees. This adoption 
Published in IEEE Transactions on Professional Communication, 56 (2) p. 160-175

challenge was mentioned in terms of becoming familiar with the technology, creating standards to work with the technology, and willingness of employees to work with Virtual Worlds. Many interviewees mentioned one important aspect hindering adoption of professional Virtual Worlds; the fact that the Virtual World was perceived as a game or play and was not perceived as work. The current professional Virtual Worlds are often not yet perceived as serious communication tools.

Technological Standards: Moreover, the adoption and wide spread use of Virtual Worlds for distributed work was challenged by technical issues. This was a strong sub-theme $(72 \%)$ including topics such as lacking standards across the virtual worlds, having enough bandwidth and having insufficient graphical cards in participants' computers. Especially Asian interviewees complained about the lack of bandwidth in for example India and Taiwan. Interviewees discussed the ease of use, which differs very much per platform. Furthermore, interoperability between platforms is currently hardly possible.

Lack of Natural Gestures of Avatars: Although the avatar usage in professional Virtual Worlds was perceived as beneficial, the interviewees disliked the fact that many of the current professional Virtual World platforms do not provide avatars with natural movements and users' gestures. Furthermore, facial expressions cannot be naturally conveyed via the interface. This was considered as a weak sub-theme as $36 \%$ of the interviewees mentioned these aspects as problematic. Especially in cases of distributed work and when people have not met face-to-face it is important to understand facial expressions and non-verbal signs. 
Published in IEEE Transactions on Professional Communication, 56 (2) p. 160-175 Experience In Using Virtual Worlds And Other Social Networking Or Gaming Tools: It became clear from the data that the more experience people have in working with Virtual Worlds, the easier they can work with these environments. Also the experience in using different types of platforms, such as online games and social media, and not only traditional ICT tools, seemed to be important in adopting the virtual world technology. Some interviewees mentioned that different people face different challenges in adopting Virtual Worlds based on their experience and interest in web 2.0 technologies, such as online games and social media. This was a weak sub-theme stated by $49 \%$ of the interviewees.

With the in-depth interview data from companies using Virtual Worlds we could answer our research questions on how professional Virtual Worlds are used and experienced as a communication media for global distributed work. Companies use professional Virtual Worlds for a number of use cases, in which the strongest use case was training, and others were small team meetings, social network and community building, and conferences. Important themes related to our second research question on how Virtual Worlds support global professional communication were that the professional Virtual Worlds enable global and distributed work through various features and experiences of participants, as well as support visualization of content and learning.

\section{CONCLUSIONS, LIMITATIONS AND SUggeSTIONS FOR FUTURE WORK}

The purpose of this section is to conclude the findings, present the limitations of the study, and future work possibilities. The following subsections are presented: conclusions, limitations and suggestions for future work.

Conclusions This study presents an insight in the current use and experiences of global managers applying professional Virtual Worlds and how these Virtual Worlds support global 
Published in IEEE Transactions on Professional Communication, 56 (2) p. 160-175

professional communication.

We found four main use cases for professional Virtual Worlds that supported geographically dispersed and global communication and collaboration, as well as visualization of data and information and learning. The findings show that a number of characteristics of Virtual Worlds are perceived to support distributed professional and technical communication better than traditional CMC. The possibility to visualize content in $3 \mathrm{D}$, to have a social presence in the Virtual World through avatars, and being able to have a joint space support distributed and global work groups in their communication. Our findings confirm literature on Virtual Worlds possibility to support learning and training. However, next to the options for using Virtual Worlds professionally, we also found a number of challenges that hinder large-scale implementation of Virtual Worlds in professional global contexts. The primary challenges are adoption challenges as well as technical challenges.

Limitations This study gives an insight into professional Virtual Worlds, but is of explorative nature and limited towards generalizations of the findings. One of the major limitations of the study was that we primarily interviewed managers who were experienced in using Virtual Worlds in a global context. We only received the manager's input and interpretation on how the Virtual Worlds were used in their work and teams, but did not focus on how the teams worked with Virtual World during their normal working days. Therefore, our findings reflect the perceptions of expert users who were usually very motivated and interested in Virtual Worlds. However, as adaptation of technology always involves the presence of key users, our informants form a representative sample to study professional use of Virtual Worlds.

Suggestions for future research Over time more studies are needed on how companies are 
Published in IEEE Transactions on Professional Communication, 56 (2) p. 160-175

actually using these Virtual Worlds for professional communication in a distributed context, and how Virtual Worlds are applied together with other CMC tools. Based on the findings of this study, future research could look into the business value of professional Virtual Worlds in relation to other tools for distributed work, as well as look into aspects like anonymity, creativity, and identity, which might be important for distributed settings.

Important for future research and for companies would be to define clear measurements for studying the effects of Virtual Worlds and to conduct studies in which Virtual Worlds are related to other ICT that is used for distributed work. Even though the use of Virtual Worlds shows a decrease in travel costs and travel time, and a perceived productivity increase, the cost for developing, maintaining and training people to use the Virtual World are rather high. Unclear is still, how large of a competitive advantage Virtual Worlds can offer in either costs or knowledge sharing and learning for distributed work in relation to other ICT.

Another important issue for the development and adoption of professional Virtual Worlds is the users' ability to work in a safe ICT environment (behind firewall) that is connected to social network sites or employees' profile sites. In such a way the professional Virtual World can be a communication tool in combination with other distributed work tools in order to create a better working environment. Even though most typical collaboration settings in organizations often require some sort of authentication of users, the professional Virtual Worlds can also be applied for more anonymous collaboration. Anonymous collaboration has been found especially beneficial when power or status differences exist in organization [59]. It would be interesting to study the use of Virtual Worlds as communication tool on social behavior, power and status in global distributed organizations, as well as the impact of avatar representation for professional tasks and performance. Finally future work could research the 
Published in IEEE Transactions on Professional Communication, 56 (2) p. 160-175

developing and maintaining of trust in distributed teams [53] with help of avatars and Virtual Worlds.

\section{REFERENCES}

[1] P. Hinds and S. Kiesler, Eds., "Distributed Work," Cambridge: The MIT Press, USA, 2002.

[2] L.L. Martins, L.L. Gilson and M.T. Maynard, "Virtual teams: What do we know and where do we go from here?," Journal of Management, vol. 30, no. 6, pp. 805-835, 2004.

[3] M.B. O’Leary and J.N. Cummings, “The spatial, temporal, and configurational characteristics of geographic dispersion in teams," MIS Quarterly, vol. 31, no. 3, pp. 433452, 2007.

[4] T.L. Griffith, J.E. Sawyer and M.A. Neale, "Virtualness and knowledge in teams: Managing the love triangle of organizations, individuals, and information technology," MIS Quarterly, vol. 27, no. 2, pp. 265-287, 2003.

[5] M.B. Watson-Manheim, K. Chudoba and K. Crowston, "Discontinuities and continuities: a new way to understand virtual work," Information Technology and People, vol. 15, no. 3, pp. 191-209, 2002.

[6] D. Armstrong and P. Cole, "Managing distances and differences in geographically distributed work groups," in Distributed Work, P. Hinds, S. Kiesler, Eds. Cambridge: MIT Press, 2002, pp.167-186.

[7] P.M. Bosch-Sijtsema, R. Fruchter, M. Vartiainen and V. Ruohomäki, “A framework to analyze knowledge work in distributed teams," Group \& Organization Management Journal, vol. 36, no. 3, pp. 275 - 307, 2011. 
Published in IEEE Transactions on Professional Communication, 56 (2) p. 160-175

[8] P.E. Brewer, "Miscommunication in International Virtual Workplaces: A Report on a Multicase Study," IEEE Transaction of Professional Communication, vol. 53, no. 4, pp. $329-345,2010$.

[9] S.L. Connaughton and M. Shuffler, "Multinational and Multicultural Distributed teams. A Review and Future Agenda,” Small Group Research, vol. 38, no. 3, pp. 387-412, 2007.

[10] C.D. Cramton and P.J. Hinds, “ Intercultural interaction in distributed teams: Salience of and adaptations to cultural differences," in Proceedings of the Academy of Management Annual Meeting, Best Papers, G. Salomon, Ed., Philadelphia, PA, August 3-8, 2007.

[11] J.A. Espinosa, J.N. Cummings, J.M. Wilson and B.M. Pierce "Team boundary issues across multiple global firms," Journal of Management Information Systems, vol. 19, no. 4, pp.157-190, 2003.

[12] S. Kiesler and J.N. Cummings, "What do we know about proximity and distance in work groups? A legacy of research," in Distributed work, P. Hinds and S. Kiesler Eds., Boston: MIT Press, 2002, pp. 57-81.

[13] G.M. Olson and J.S. Olson, "Distance matters," Human-Computer Interaction, 15, pp.139-178, 2000.

[14] J. Sutanto, A. Kankanhalli and B.C.Y. Tan, "Deriving IT-Mediated Task Coordination Portfolios for Global Virtual Teams," IEEE Transactions of Professional Communication, vol. 54, no. 2, pp. 133 - 151, 2011.

[15] K.M. Chudoba, E. Wynn, M. Lu and M.B. Watson-Manheim, "How virtual are we? Measuring virtuality and understanding its impact in a global organization," Information Systems Journal, vol. 15, pp. 279-306, 2005.

[16] G. DeSanctis and P. Monge, "Introduction to the special issue: communication processes for virtual organizations," Organization Science, vol. 10, pp. 693-703, 1999. 
Published in IEEE Transactions on Professional Communication, 56 (2) p. 160-175

[17] A. Majchrzak, R.E. Rice, A. Malhotra, N. King and S. Ba, "Technology Adaptation: The Case of a Computer-Supported Inter-Organizational Virtual Team,” MIS Quarterly, vol. 24, no. 4, pp. 569-600, 2000.

[18] R.L. Daft and R.H. Lengel, "Information richness: a new approach to managerial behavior and organization design," in Information and Cognition in organization, L.L. Cummings and B.M. Staw Eds., Greenwich Connecticut: JAI Press Inc, pp. 243-285, 1990.

[19] E-L. Sallnäs, "Mode on Social Presence, Virtual Presence, and Performance in Collaborative Virtual Environments," Presence, vol. 14, no. 4, pp. 434-449, 2005.

[20] A. Sivunen and M. Hakonen, "Review of Virtual Environment Studies on Social and Group Phenomena: Trends and Agenda for Further Research," Small Group Research, vol. 42, pp. 405-457, 2011

[21] N. Yee and J. Bailenson, "The Proteus Effect: The effect of transformed selfrepresentation on behavior," Human Communication Research, vol. 33, no. 3, pp. 271-290, 2007.

[22] A. Davis, J. Murphy, D. Owens, D. Khazanchi and I. Zigurs, "Avatars, people, and virtual worlds: foundations for research in metaverses," Journal of the Association of Information Systems, vol. 10, no. 2, pp. 90-117, 2009.

[23] kZero, "Virtual world registered accounts reach 1.7bn in Q4 2011. Retrieved in March 22, 2012 from: http://www.kzero.co.uk/blog/

[24] P.R. Messinger, E., Stroulia, K. Lyons, M. Bone, R.H. Niu, K. Smirnov and S. Perelgut, "Virtual worlds - past, present, and future: New directions in social computing," Decision Support Systems, vol. 47, pp. 204-228, 1990.

[25] K.L. Nowak and F. Biocca, "The effect of the agency and anthropomorphism on users' sense of telepresence, copresence, and social presence in virtual environments," Presence, Vol. 12, pp. 481-494, 2003. 
Published in IEEE Transactions on Professional Communication, 56 (2) p. 160-175

[26] J. Peña, J.T. Hancock and N.A. Merola, "The priming effects of avatars in virtual settings," Communication Research, vol. 36, pp. 838-856, 2009.

[27] N. Yee and J.N. Bailenson "The difference between being and seeing: The relative contribution of self-perception and priming to behavioral changes via digital selfrepresentation," Media Psychology, vol.12, pp. 195-209, 2009.

[28] A.-S. Axelsson, Å Abelin, I. Heldal, R. Schroeder and J. Wideström, "Cubes in the cube: A comparison of a puzzle-solving task in a virtual and a real environment," CyberPsychology \& Behavior, vol. 4, pp. 279-286, 2001.

[29] C.L. Hoyt, J. Blascovich and K.R. Swinth, "Social inhibition in immersive virtual environments," Presence, vol. 12, pp. 183-195, 2003.

[30] M. Slater, A. Sadagic, M. Usoh and R. Schroeder, "Small-group behavior in a virtual and real environment: A comparative study," Presence, vol. 9, pp. 37-51, 2000.

[31] J.N. Bailenson and N. Yee, “A longitudinal study of task performance, head movements, subjective report, simulator sickness, and transformed social interaction in collaborative virtual environments," Presence, vol. 15, pp. 699-716, 2006.

[32] W.L. Heinrich, P. Youngblood, P.M. Harter and P. Dev, "Simulation for team training and assessment: case studies of online training with virtual worlds," World Journal of Surgery, vol. 32, pp.161-170, 2008.

[33] S. Bronack, R. Sanders, A. Cheney, R.Riedl, J. Tashner, and N. Matzen, "Presence Pedagogy: Teaching and Learning in a 3D Virtual Immersive World," International Journal of Teaching and Learning in Higher Education, vol. 20, no. 1, pp. 59-69, 2008.

[34] E.Prasolova-Førland, "Analyzing place metaphors in 3D educational collaborative virtual environments", Computers in Human Behavior, vol. 24, 185-204, 2008. 
Published in IEEE Transactions on Professional Communication, 56 (2) p. 160-175

[35] J. Li, D. D’Souza and D. Yunfei, "Exploring the Contribution of Virtual Worlds to Learning in Organizations," Human Resource Development Review, vol. 10, no. 3, pp. 264-285, 2011.

[36] D. Pollitt, "Learn-while-you-play program gets IBM recruits up to speed," Human Resource Management International Digest, vol. 15, no. 4, 14-15, 2007.

[37] W. Ritke-Jones, Eds., "Virtual Environments for Corporate Education: Employee Learning and Solutions," Hershey: IGI Global Publications, 2010.

[38] R. Kark, "Games Managers Play: Play as a form of leadership development," Academy of Management Learning and Education, vol. 10, no. 3, pp. 507-527, 2011.

[39] A. Lantz, "Meetings in a distributed group of experts: Comparing face-to-face, chat and collaborative virtual environments," Behaviour \& Information Technology, vol. 20, pp. $111-117,2001$.

[40] F. Bélanger and C.D. Allport, "Collaborative technologies in knowledge telework: an exploratory study," Information Systems Journal, vol. 18, no. 1, pp.101-121, 2008.

[41] D. Williams, S. Caplan and L. Xiong, "Can you hear me now? The impact of Voice in an online gaming community," Human Communication Research, vol. 33, pp. 427-449, 2007.

[42] D. Dalgarno and M.J.W. Lee, "What are the learning affordances of 3-D virtual environments?” British J of Educational Technology, vol. 41, no. 1, pp.10-32, 2010.

[43] S. van der Land, A. P. Schouten, B. van den Hooff and F. Feldberg, "Modeling the Metavers: A theoretical model of effective team collaboration in 3D virtual environments," Journal of Virtual Worlds Research, vol. 4, no. 3, pp.1-16, 2011.

[44] A. Sivunen, "Strengthening Identification with the Team in Virtual Teams: The Leaders' Perspective," Group Decision and Negotiation, vol. 15, no. 4, pp. 345-366, 2006. 
Published in IEEE Transactions on Professional Communication, 56 (2) p. 160-175

[45] M.B. Miles and M.A. Huberman, "Qualitative data analysis: A sourcebook of new methods," Beverly Hills, CA: Sage, 1984.

[46] M. R. Easterby-Smith, R. Thorpe and A. Lowe "Introduction to Management Research,” London: Sage, 1991.

[47] K. Locke, “Grounded theory in management research,” London: Sage, 2001.

[48] Y.S. Lincoln and E.G. Guba, Naturalistic Inquiry, Beverly Hills: Sage, 1985.

[49] B. G. Glaser and A. L. Strauss, The Discovery of Grounded Theory, Chicago, IL:

Aldine, 1967.

[50] B.A. Nardi and S. Whittaker, "The place of face-to-face communication in distributed work," in Distributed work, P. Hinds and S. Kiesler, Eds., Boston: MIT Press, 2002, pp. 83-110.

[51] W.F. Boh, Y. Ren, S. Kiesler and R. Bussjaeger, "Expertise and Collaboration in the Geographically Dispersed Organization," Organization Science, vol. 18, no. 4, pp. 595$612,2007$.

[52] M.T. Hansen, "The search-transfer problem: The role of weak ties in sharing knowledge across organization subunits," Administrative Science Quarterly, vol. 44, pp. 82-111, 1999.

[53] S.L. Jarvenpaa, K. Knoll and D.E. Leidner, "Is Anybody Out There? Antecedents of Trust in Global Virtual Teams," Journal of Management Information Systems, vol. 14, no. 4 pp. 29-64, 1998.

[54] J. Baker, D.R. Jones and J. Burkman, "Using visual representations of data to enhance sensemaking in data exploration tasks," Journal of the Association of Information Systems, vol. 10, no. 7, pp. 533-559, 2009.

[55] J. Whyte, B. Ewenstein, M. Hales and J. Tidd, "Visualizing knowledge in projectbased work," Long Range Planning, vol. 41, pp. 74-92, 2008. 
Published in IEEE Transactions on Professional Communication, 56 (2) p. 160-175

[56] L. Argote and P. Ingram, "Knowledge transfer: a basis for competitive advantage in firms," Organizational Behavior and Human Decision Processes, vol. 82, no. 1, pp. 150$169,2000$.

[57] S. Yamnill and G. N. McLean, "Theories supporting transfer of training," Human Resource Development Quarterly, vol. 12, no. 2, pp. 195-208, 2001.

[58] W.J. Orlikowski, "Knowing in practice: Enacting a collective capability in distributed organizing," Organization Science, vol. 13, no. 3, pp. 249-273, 2000.

[59] J.F. Nunamaker, A.R. Dennis, J.S. Valacich, D.R. Vogel and J.F. George, "Electronic meeting systems to support group work," Communications of the ACM, vol. 34, pp. 40-61, 1991. 